\title{
PERENCANAAN PERSEDIAAN BAHAN BAKU UNTUK RAK GANTUNGAN BAJU DI UD. WS.
}

\author{
Rizki Febrianto \\ Teknik Industri, Fakultas Teknik \\ Universitas Maarif Hasyim Latif, Sidoarjo, Indonesia \\ e-mail : rizki-febrianto@student.umaha.ac.id
}

\begin{abstract}
ABSTRAK
UD. WS adalah usaha menengah masyarakat yang bergerak di dalam bidang industri pembuatan rak gantungan baju. Dalam proses produksi perlu adanya perencanaan pengadaan bahan baku. Hal yang harus dilakukan adalah pemesanan dan pembelian bahan baku. Agar produksi sesuai dengan proses, modal dan dana yang dipakai dalam persediaan diperlukan perencanaan yang tepat. Ketepatan dalam suatu persediaan yaitu dengan membeli bahan baku dengan kualitas yang bagus. Teknik analisis yang digunakan dalam pengolahan data adalah permintaan sebelumnya, peramalan dan Material Requirement Planning. Teknik peramalan menggunakan 2 metode yaitu Exponential Smoothing dan Linier Regression. Perhitungan Lot Sizing Menggunakan metode Economic Order Quantity, Lot for Lot, Period Order Quantity, Part Period Balancing, dan Wagner Whitin. Hasil penelitian dapat diambil kesimpulan bahwa penerapan metode Lot Sizing Lot for Lot untuk setiap bahan baku rak gantungan baju dapat meminimalkan biaya semua persediaan bahan baku jika dibandingkan metode yang lainnya.
\end{abstract}

Kata kunci: Inventori, Lot Sizing, Material Requirement Planning, Persediaan Bahan Baku

\section{PENDAHULUAN}

Dalam persaingan industri yang sangat ketat dari satu perusahaan dengan yang lainnya maka banyak perusahaan yang menerapkan suatu pengendalian terhadap persediaan bahan baku secara benar dan tepat agar perusahaan dapat mengontrol pembelian dan pemakaian bahan baku secara benar sesuai dengan perencanaan yang diinginkan.

Proses produksi dalam perusahaan itu sangat penting karena produksi merupakan langkah utama dalam sebuah penyelesain produk. Prse produksi merupakan proses untuk mengolah bahan-bahan baku agar menjadi barang jadi yang memberi keuntungan bagi perusahaan. Jika suatu produksi dapat dijalankan sesuai dengan rencana perusahaan maka hal itu sangat berpengaruh pada laba yang diperoleh perusahaan. Maka dari itu agar sebuah proses produksi bisa dijalankan dengan lancar harus terdapat adanya bahan baku yang sesuai dengan permintaan.

Banyak perusahaan yang melakukan perencanaan pengendalian bahan baku untuk menekan biaya agar memperoleh keuntungan seperti halnya UD. WS. UD. WS adalah usaha menengah masyarakat yang bergerak di dalam bidang industri pembuatan rak gantungan baju.
Untuk dapat memproduksi produk-produk tersebut maka perlu adanya perencanaan pengadaan bahan baku. Bahan-bahan yang harus disediakan dalam pembuatan rak gantungan baju adalah pipa kotak dengan ukuran $2 \times 4 \mathrm{~cm}$, plat ukuran 4 x $8 \mathrm{~cm}$, mur baut ukuran kunci $12 \mathrm{~mm}$, pipa kotak ukuran persegi $1,5 \times 1,5 \mathrm{~cm}$, kawat $\emptyset 3$ mm. Agar produksi sesuai dengan proses dan modal yang di gunakan, maka dalam persediaan bahan baku harus dilakukan perencanaan yang tepat. Metode Material Requirement Planning (MRP), merupakan metode yang digunakan untuk mengalokasikan kebutuhan persediaan bahan baku agar sesuai perencanaan dan penjadwalan produksi. Dengan memakai metode MRP di UD. WS akan dapat memenuhi kebutuhan produksi untuk pembuatan produk jadi. sehingga sebuah proses produksi akan lancar, tidak terganggu dan bisa menghemat biaya yang sudah dikeluarkan untuk pembelian-pembelian bahan baku. Selain itu perusahaan juga dapat mengurangi biaya penyimpanan, karena pengalokasian ruang penyimpanan yang sesuai dengan kebutuhan produksi.

Menurut (Nuriszal \& Anshori, 2019) perhitungan lot sizing yang paling tepat digunakan untuk menyelesaikan permasalahan adalah period order quantity. Penelitian dari (Tyas \& Anshori, 
2019) mengenai pengelolaan persediaan dengan distributor, dengan menerapkan metode JELS (Joint Economic Lot Size). Dan penelitian ini menghasilkan total biaya yang efisien lebih kecil. Selanjutnya penelitian dari (Wijayanti \& Adriansyah, 2019) berdasarkan hasil analisis metode yang paling efisien untuk setiap bahan baku adalah metode lot for lot.

\section{METODE PENELITIAN}

(Rovianty, 2007) Dalam penerapan penelitian ini ada beberapa yang di oerlukan dalam MRP :

1. Jadwal induk produksi yaitu perencanaan pada suatu fase yang memilih berapa banyak serta kapan perusahaan merencanakan, menghasilkan tiap produk akhir. JIS terbuat dari cara membagi rencana produksi total pada beberapa produk akhir yang akan dibuat, dimana ramalan yang digunakan untuk membuat rencana produksi jangka pendek. JIS artinya proses alokasi dalam membuat sebuah produk yang direncanakan dalam memperhatikan kapasitas yang ada.

2. Struktur produk yaitu daftar item yang diharapkan untuk membentuk satu unit produk jadi. Struktur produk disebut Bill of materiall (BOM), berisi tentang penjabaran dari sebuah produk. Tidak hanya mencantumkan data tentang bahan standar serta item tetapi juga mencantumkan tentang urutan-urutan produksi.

3. Catatan daftar persediaan adalah catatan tentang persediaan item yang terdapat pada gudang serta yang telah dipesan tapi belum sampai.

\section{Model-model penentuan ukuran lot}

a. Teknik Lot for Lot adalah teknik yang menghasilkan secara sempurna berapa kebutuhan bahan standar yang dibutuhkan. Teknik ini konsisten menggunakan sasaran MRP yaitu memenuhi keinginan permintaan yang bersifat terikat. Jika pesanan yang acapkali terjadi hemat dan teknik persediaan just in time diterapkan, maka teknik ini sangat efisien, sebaliknya bila biaya set up relatif besar maka teknik ini menjadi mahal. (Heizer \& Render, 2006)

b.Teknik Economic Order Quantity yaitu statistik yang menggunakan data homogen rata-rata. Jadi teknik ini sebenarnya lebih cocok digunakan di saat permintaan bebas. MRP lebih sesuai pada jenis permintaan terikat. (Heizer \& Render, 2006)

c. Teknik Period Order Quantity disebut sebagai metode uniform order style yaitu pengembangan asal EOQ untuk jumlah permintaan yang tidak sama dalam beberapa periode. Rata-rata hasil permintaan dipergunakan dalam contoh EOQ untuk menerima rata-rata hasil permintaan per periode serta hasilnya dibulatkan kedalam angka integer. Nomor terakhir untuk menunjukkan jumlah periode ketika yang dicakup untuk setiap kali pemesanan. (Herjanto, 2007)
d.Teknik Part Period Balancing ialah pendekatan yang dinamis untuk menyeimbangkan biaya set up dan penyimpanan. PPB memakai info tambahan menggunakan pembaruan ukuran lot untuk menggambarkan kebutuhan berukuran lot berikutnya pada masa yang akan datang. PPB mencoba menyeimbangkan biaya set up dan penyimpanan agar permintaan dapat diketahui. Penyeimbangan sebagian periode membentuk sebuah economic part period atau sebagian periode hemat. Yang artinya perbandingan antara biaya set up dengan biaya penyimpanan. (Heizer \& Render, 2006)

e.Teknik Algoritma Wagner Whitin yaitu memakai mekanisme meningkatkan secara optimal yang didasari contoh program dinamis dalam menambahkan beberapa kerumitan di perhitungan ukuran lot. Prosedur ini mengasumsikan dalam hal horizon waktu yang terbatas di luar kendali pada mana tidak ada yang butuh higienis tambahan. Mekanisme ini memberikan hasil yang baik. Tujuannya yaitu untuk mendapatkan seni manajemen pemesanan yang baik untuk total jadwal kebutuhan higienis dengan jalan meminimalkan total ongkos pengadaan dan ongkos simpan. dalam pemenuhan kebutuhan bersih satu periode yang ada di horizon perencanaan agar memberikan jawaban optimal. (Heizer \& Render, 2006)

MRP adalah jenis permintaan terikat yang menggunakan daftar bahan yang dibutuhkan, status persediaan, penerimaan yang direncanakan, serta jadwal produksi induk, yang digunakan untuk memilih kebutuhan material yang akan digunakan. (Heizer \& Render, 2006)

(Herjanto, 2007) Tujuan MRP yaitu :

a.Meminimumkan persediaan dari suatu item yang diperlukan sesuai dengan JIS.

b. Mendorong tingkat efisiensi yang tinggi jumlah persediaan, saat produksi, dan juga ketika perencanaan pengiriman barang dilakukan dengan baik sesuai jadwal induk produksi.

c. Dapat mengurangi segala resiko saat pengiriman dan produksi yang telah diidentifikasikan banyaknya bahan dan item yang diperlukan baik berasal dari segi jumlah serta waktunya menggunakan.

\section{HASIL DAN PEMBAHASAN}

\section{Proses Produksi}

Proses produksi yang dijalankan pada UD

WS dapat disimpulkan dibawah ini :

1. Proses 1, Dari penyimpanan bahan baku, bahan di bawa ke mesin untuk dipotong sesuai dengan ukuran dan bahan yang di potong yaitu pipa $2 \times 4$, pipa $1.5 \times 1.5$, dan kawat bendrat.

2. Proses 2, Setelah ketiga bahan baku tersebut dipotong, selanjutnya ketiga bahan baku tersebut di bor sesuai dengan ukuran masing-masing yang telah ditetapkan. 
3. Proses 3 , Selanjutnya bahan baku plat $4 \times 8$ di las/disambungkan ke salah satu dari bagianbagian pipa $2 \times 4$, dan semua bahan di las lalu dirangkai menjadi rak gantungan baju.

4. Proses 4, setelah produk di las dan dirangkai maka kemudian produk akan dilakukan proses finishing atau proses terakhir dari rangkaian produksi tersebut, finisihing tersebut yaitu dinamakan coating, coating merupakan proses pengecatan dengan bahan serbuk cat yang memiliki proses pemanasan atau oven setelah disemprotkan melalui alat untuk mengecat atau melalui kompresor.

5. Proses 5, setelah semua proses produksi selesai maka tahap selanjutnya yaitu pengemasan, pengemasan produk di lakukan dengan membungkus produk akhir dengan bahan plastik untuk melindungi produk tersebut.

6. Proses terakhir yaitu pemindahan produk dari tempat produksi ke dalam gudang penyimpanan produk jadi.

\section{Struktur Produk}

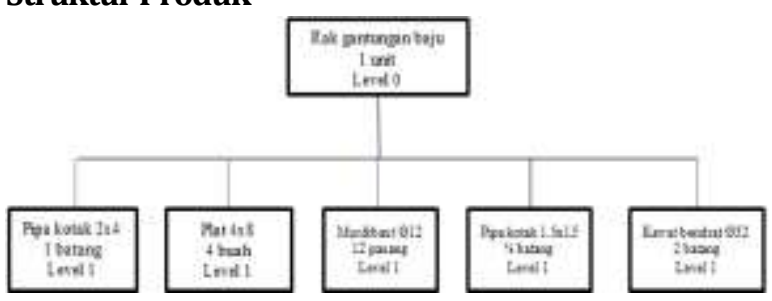

Gambar 1. Struktur produk

\section{Bill of Material}

Tabel 1. Bill of Material jumlah

\begin{tabular}{|c|c|c|c|}
\hline Level & Nama Barang & Jumlah & satuan \\
\hline 0 & Rak gantungan baju & 1 & unit \\
\hline 1 & Pipa Kotak $2 \times 4$ & 1 & Batang \\
\hline 1 & plat $4 \times 8$ & 4 & Buah \\
\hline 1 & mur \& baut & 12 & Pasang \\
\hline 1 & Pipa kotak 1.5x1.5 & $1 / 2$ & Batang \\
\hline 1 & Kawat bendrat & 2 & Batang \\
\hline
\end{tabular}

Dari Tabel 1, dapat diketahui bahwa pada level 0 atau 1 unit produk rak gantungan baju membutuhkan material pipa kotak 2 × 4 sebanyak 1 batang, plat 4 × 84 buah, mur dan baut $\emptyset 12$ sebanyak 12 pasang, pipa kotak 1.5 x 1.5 sebanyak $1 / 2$ batang, dan kawat bendrat sebanyak 2 batang.

\section{Permintaan}

Dalam memproduksi rak gantungan baju sistem yang digunakan adalah berdasarkan pesanan atau make to order yang berarti hanya memproduksi saat menerima pesanan atau permintaan dari konsumen. Pesanan harus dilakukan beberapa periode sebelumnya, produksi akan dilakukan berdasarkan data histori pesanan konsumen yang sudah berlalu seperti yang ada dalam tabel berikut ini :

Tabel 2. Data Permintaan

\begin{tabular}{|c|c|}
\hline Bulan & $\begin{array}{c}\text { Jumlah Permintaan } \\
\text { (unit) }\end{array}$ \\
\hline Juni 2018 & 250 \\
\hline Juli 2018 & 175 \\
\hline Agustus 2018 & 175 \\
\hline September & 175 \\
\hline Oktober 2018 & 175 \\
\hline November & 175 \\
\hline desember 2018 & 200 \\
\hline januari 2019 & 200 \\
\hline februari 2019 & 200 \\
\hline maret 2019 & 250 \\
\hline April & 250 \\
\hline mei 2019 & 250 \\
\hline Total & 2475 \\
\hline Rata-rata & 206.25 \\
\hline
\end{tabular}

Berdasarkan tabel diatas jika dirubah bentuk pola dengan menggunakan software excel maka akan tampak seperti gambar ini :

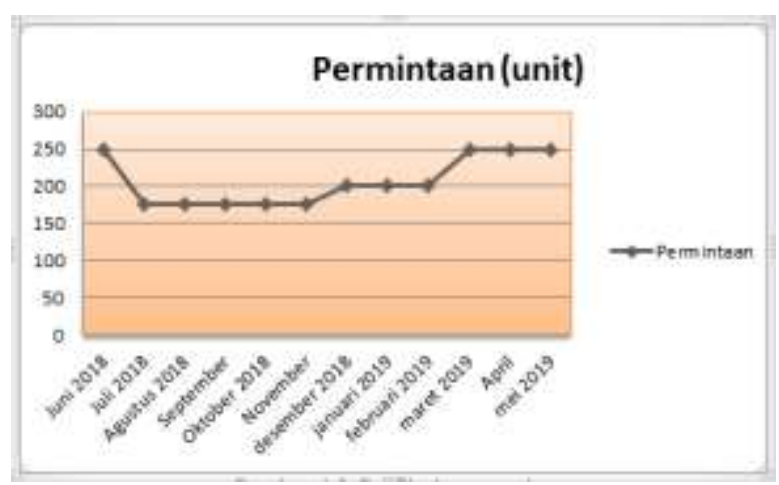

Gambar 2. Grafik data permintaan

Biaya-biaya Persediaan

Tabel 3. Harga bahan baku \& biaya pesan

\begin{tabular}{|c|c|c|c|c|}
\hline No & Nama Barang & Harga & Satuan & biaya pesan \\
\hline 1 & pipa kotak $2 \times 4$ & Rp. 40.000 & /batang & Rp 5.000 \\
\hline 2 & plat 4x8 & Rp. 600 & /buah & Rp 5.000 \\
\hline 3 & mur\&baut & Rp 200 & /pasang & Rp. 5000 \\
\hline 4 & $\begin{array}{c}\text { pipa kotak } \\
1,5 \times 1,5\end{array}$ & Rp. 32.000 & /batang & Rp 5.000 \\
\hline 5 & kawat bendrat & Rp 7.000 & /batang & Rp 5.000 \\
\hline
\end{tabular}

\section{Biaya Simpan}

Biaya penyimpanan dihitung berdasar presentase harga yang disimpan tiap bulannya. Biaya penyimpanan meliputi :

Biaya kerusakan dan kehilangan : $10 \%$

Biaya penanganan persediaan : $4 \%$

Biaya fasilitas penyimpanan $\quad: 10 \%$

Total biaya penyimpanan : $24 \%$ dari harga bahan 
Tabel 4. Biaya simpan

\begin{tabular}{|c|c|c|c|}
\hline Bahan baku & $\begin{array}{c}\text { Biaya simpan } \\
\text { /bulan }\end{array}$ & $\begin{array}{c}\text { Biaya } \\
\text { simpan } \\
\text { /tahun }\end{array}$ & Satuan \\
\hline pipa kotak 2x4 & Rp. 9.600 & Rp. 115.200 & /batang \\
\hline plat 4x8 & Rp. 144 & Rp. 1.728 & /buah \\
\hline mur\&baut & Rp. 48 & Rp. 576 & /pasang \\
\hline $\begin{array}{c}\text { pipa kotak } \\
1,5 \times 1,5\end{array}$ & Rp. 7680 & Rp. 92.160 & /batang \\
\hline kawat bendrat & Rp. 1.680 & Rp. 20.160 & $/$ batang \\
\hline
\end{tabular}

\section{Peramalan}

Berdasarkan data permintaan masa lalu dalam tabel 2 maka disimpulkan bahwa jumlah permintaan tidak menentu atau acak. Penelitian ini metode peramalan yang digunakan adalah exponensial smoothing dan linier regression. Peramalan dilakukan dengan aplikasi bernama software POM dari aplikas For Windows 3. Berdasarkan dengan perhitungan yang telah dilakukan, metode linier regression memiliki standar error yang lebih kecil dibandingkan dengan metode exponential smoothing. Maka dari itu metode linier regression yang digunakan sebagai data peramalan permintaaan untuk bulan berikutnya, serta dijadikan sebagai jadwal induk produksi (JIP).

\section{Jadwal induk Produksi}

Tabel 5. Jadwal induk produksi

\begin{tabular}{|c|c|}
\hline Bulan & $\begin{array}{c}\text { Peramalan } \\
\text { Permintaan } \\
\text { (unit) }\end{array}$ \\
\hline Juni & 179 \\
\hline Juli & 184 \\
\hline Agustus & 189 \\
\hline September & 194 \\
\hline Oktober & 199 \\
\hline November & 204 \\
\hline Desember & 209 \\
\hline Januari & 214 \\
\hline Februari & 219 \\
\hline Maret & 224 \\
\hline April & 229 \\
\hline Mei & 234 \\
\hline Total & 2478 \\
\hline
\end{tabular}

Dari hasil peramalan yang telah diperoleh maka dapat ditentukan jadwal induk produksi dan kebutuhan bahan baku untuk pemesanan dalam satu periode.

\section{Data Persediaan Gudang}

Tabel 6. Persediaan \& lead time

\begin{tabular}{|c|c|c|c|}
\hline Nama & $\begin{array}{c}\text { Persediaan } \\
\text { gudang }\end{array}$ & Satuan & $\begin{array}{c}\text { Lead } \\
\text { time }\end{array}$ \\
\hline $\begin{array}{c}\text { Rak gantungan } \\
\text { baju }\end{array}$ & - & - & - \\
\hline Pipa Kotak $2 \times 4$ & 180 & Batang & 1 hari \\
\hline plat 4x8 & 720 & Buah & 1 hari \\
\hline mur \& baut & 2,160 & Pasang & 1 hari \\
\hline $\begin{array}{c}\text { Pipa kotak } \\
1.5 x 1.5\end{array}$ & 90 & Batang & 1 hari \\
\hline Kawat bendrat & 360 & Batang & 1 hari \\
\hline
\end{tabular}

\section{Perhitungan Kebutuhan Bersih}

Tabel 7. Kebutuhan bersih

\begin{tabular}{|c|c|c|c|c|c|c|}
\hline \multirow[b]{2}{*}{ Peniode } & \multicolumn{5}{|c|}{ Bahan Baku } & \multirow{2}{*}{$\begin{array}{c}\text { Rencana produks } \\
\text { Unit }\end{array}$} \\
\hline & $\begin{array}{c}\text { Pipa kotak } \\
2 \mathrm{x} 4 \\
\text { (batang) }\end{array}$ & $\begin{array}{l}\text { Plat } 4 \times 8 \\
\text { (buah) }\end{array}$ & $\begin{array}{c}\text { Murobaut } \\
\text { (pasang) }\end{array}$ & $\begin{array}{c}\text { Pipa kotak } \\
1.5 \times 1.5 \\
\text { (batang) }\end{array}$ & $\begin{array}{l}\text { Kawat } \\
\text { bendrat } \\
\text { (batang) }\end{array}$ & \\
\hline Juni 19 & 179 & 716 & 2.148 & 89,5 & 358 & 179 \\
\hline Jull 19 & 184 & 736 & 2.208 & 92 & 368 & 184 \\
\hline Agustus 19 & 189 & 756 & 2.268 & 94,5 & 378 & 189 \\
\hline September & 194 & 776 & 2.328 & 97 & 388 & 194 \\
\hline Ostober 19 & 199 & 796 & 2388 & 99,5 & 398 & 199 \\
\hline November & 204 & 816 & 2.448 & 102 & 408 & 204 \\
\hline Desember 19 & 209 & 836 & 2.508 & 104,5 & 418 & 209 \\
\hline Januan'20 & 214 & 856 & 2.568 & 107 & 428 & 214 \\
\hline Februan 20 & 219 & 876 & 2.628 & 109,5 & 438 & 219 \\
\hline Maret 20 & 224 & 896 & 2.688 & 112 & 448 & 224 \\
\hline Apnl & 229 & 916 & 2.748 & 114,5 & 458 & 229 \\
\hline Mei 20 & 234 & 936 & 2808 & 117 & 468 & 234 \\
\hline Total & 2478 & 9.912 & 29.736 & 1.239 & 4956 & 2.478 \\
\hline Rata-fata & 207 & 826 & 2478 & 103 & 413 & 207 \\
\hline
\end{tabular}

Tabel 7 menunjukkan kebutuhan bersih pada item-item total dari bulan Juni 2019 - Mei 2020 yaitu pipa kotak 2 x 4 sebanyak 2.478 batang, plat 4 x 8 sebanyak 9.912 buah, mur dan baut sebanyak 29.736 pasang, pipa kotak 1,5 x 1,5 sebanyak 1.239 batang, dan kawat bendrat sebanyak 4.956 batang.

\section{Perhitungan Lot Sizing}

Perencanaan untuk membeli bahan baku dilakukan setelah diketahui jumlah kebutuhan bersih berdasarkan item bahan baku. Metode perhitungan Lot sizing dalam penelitian ini diantaranya ialah Lot for lot, Economic Order Quantity, Periodic Order Quantity, Part Period Balancing, dan Wagner Whitin. yang dihitung dengan bantuan dari Software POM aplikasi for Windows 3. Pemilihan metode yang diterapkan selanjutnya adalah metode yang mempunyai biaya minimum dari metode yang lainnya. Dalam penentuan ukuran lot dari kelima metode diatas akan dibandingkan mana metode dari lot sizing yang paling optimal dalam menentukan persediaan bahan baku rak gantungan baju. Paling optimal dalam hal biaya minimum dan jumlah bahan yang sesuai. 
Tabel 8. Perbandingan Lot Sizing

\begin{tabular}{|c|c|c|c|c|c|}
\hline \multirow{2}{*}{ Bahan baku } & \multicolumn{5}{|c|}{ Metode Lot Sizing } \\
\hline & EOQ & LFL & POQ & PPB & $\begin{array}{c}\text { Wagner } \\
\text { W }\end{array}$ \\
\hline $\begin{array}{c}\text { pipa kotak } \\
2 \times 4\end{array}$ & $\begin{array}{c}\text { Rp. } \\
755.800\end{array}$ & $\begin{array}{c}\text { Rp. } \\
64.400\end{array}$ & $\begin{array}{c}\text { Rp. } \\
170.200\end{array}$ & $\begin{array}{c}\text { Rp. } \\
64.600\end{array}$ & $\begin{array}{c}\text { Rp. } \\
64.600\end{array}$ \\
\hline plat $4 \times 8$ & $\begin{array}{c}\text { Rp. } \\
240.656\end{array}$ & $\begin{array}{c}\text { Rp. } \\
50.576\end{array}$ & $\begin{array}{c}\text { Rp. } \\
61.912\end{array}$ & $\begin{array}{c}\text { Rp. } \\
50.576\end{array}$ & $\begin{array}{c}\text { Rp. } \\
50.576\end{array}$ \\
\hline mur\&baut & $\begin{array}{c}\text { Rp. } \\
257.592\end{array}$ & $\begin{array}{c}\text { Rp. } \\
55.576\end{array}$ & $\begin{array}{c}\text { Rp. } \\
61.912\end{array}$ & $\begin{array}{c}\text { Rp. } \\
55.576\end{array}$ & $\begin{array}{c}\text { Rp. } \\
55.576\end{array}$ \\
\hline $\begin{array}{c}\text { pipa kotak } \\
1,5 \times 1,5\end{array}$ & $\begin{array}{c}\text { Rp. } \\
485.080\end{array}$ & $\begin{array}{c}\text { Rp. } \\
58.840\end{array}$ & $\begin{array}{c}\text { Rp. } \\
101.080\end{array}$ & $\begin{array}{c}\text { Rp. } \\
58.840\end{array}$ & $\begin{array}{c}\text { Rp. } \\
58.840\end{array}$ \\
\hline $\begin{array}{c}\text { kawat } \\
\text { bendrat }\end{array}$ & $\begin{array}{c}\text { Rp. } \\
451.480\end{array}$ & $\begin{array}{c}\text { Rp. } \\
58.360\end{array}$ & $\begin{array}{c}\text { Rp. } \\
95.320\end{array}$ & $\begin{array}{c}\text { Rp. } \\
58.360\end{array}$ & $\begin{array}{c}\text { Rp. } \\
58.360\end{array}$ \\
\hline Total & $\begin{array}{c}\text { Rp. } \\
2.190 .608\end{array}$ & $\begin{array}{c}\text { Rp. } \\
287.752\end{array}$ & $\begin{array}{c}\text { Rp. } \\
490.424\end{array}$ & $\begin{array}{c}\text { Rp. } \\
287.952\end{array}$ & $\begin{array}{c}\text { Rp. } \\
287.952\end{array}$ \\
\hline
\end{tabular}

Tabel 8 menunjukkan bahwa metode lot sizing yang memiliki biaya yang paling kecil yaitu metode lot for lot dengan total biaya Rp. 287.752,-

\section{Penyusunan Tabel MRP}

Tabel 9. MRP Pipa kotak 2 x 4

\begin{tabular}{|c|c|c|c|c|c|c|c|c|c|c|c|c|c|}
\hline \multirow{3}{*}{\multicolumn{2}{|c|}{ Pipa kotak 2x4 }} & \multicolumn{12}{|c|}{ Bulan Juni 2019} \\
\hline & & \multicolumn{6}{|c|}{ Minggu 1} & \multicolumn{6}{|c|}{ Minggu 2 } \\
\hline & & 1 & 2 & 3 & 4 & 5 & 6 & 1 & 2 & 3 & 4 & 5 & 6 \\
\hline GR & & 47 & & & & & & 44 & & & & & \\
\hline $\mathrm{OH}$ & 180 & 133 & & & & & & 89 & & & & & \\
\hline \multicolumn{14}{|l|}{ NR } \\
\hline \multicolumn{14}{|l|}{ PORec } \\
\hline \multirow{2}{*}{\multicolumn{14}{|c|}{ PORel }} \\
\hline & & & & & & & & & & & & & \\
\hline & & 1 & 2 & 3 & 4 & 5 & 6 & 1 & 2 & 3 & 4 & 5 & 6 \\
\hline GR & & 44 & & & & & & 44 & & & & & \\
\hline $\mathrm{OH}$ & & 45 & & & & & & 1 & & & & & \\
\hline \multicolumn{14}{|l|}{ NR } \\
\hline \multicolumn{14}{|l|}{ PORec } \\
\hline PORel & & & & & & & & & & & & & 45 \\
\hline
\end{tabular}

Tabel 9 menunjukkan kebutuhan bahan baku pipa kotak dengan metode lot for lot pada bulan Juni 2019 minggu pertama sebesar 47 dan untuk persediaan ditangan (on hand) sebanyak 180 maka, tidak dilakukan pemesanan bahan baku karena kebutuhan pipa kotak 2 x 4 bulan Juni sebanyak 179 batang. Bulan selanjutnya kenutuhan pipa kotak sebanyak 184 batang, maka setiap minggu dilakukan pemesanan sesuai dengan jumlah produksi perminggu yaitu 46 batang.

Tabel 10. MRP Plat 4 x 8

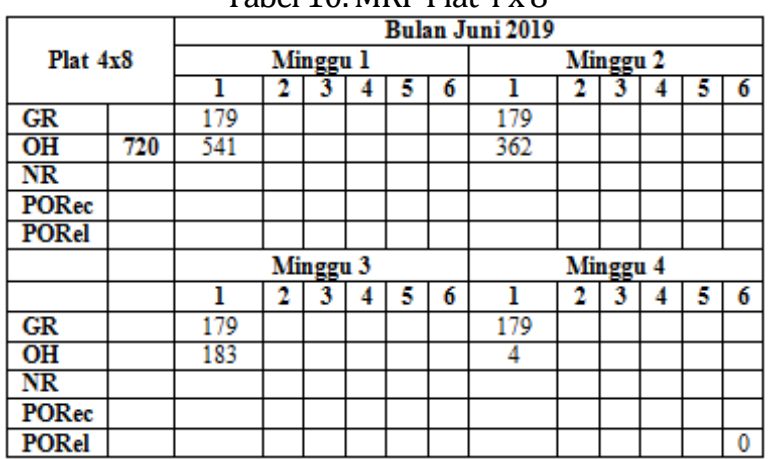

Pada bulan pertama peramalan untuk bahan baku plat 4 x 8 bulan juni 2019 dibutuhkan sebanyak 716 buah dan persediaan ditangan tersisa 720, maka untuk bulan ini tidak dilakukan pemesanan. Pemesanan dilakukan pada akhir bulan Juni 2019 karena lead time yang dibutuhkan untuk bahan ini yaitu 1 hari dan metode yang dipergunakan ialah Lot for lot, maka pesanan akan datang pada waktu awal bulan juli 2019 dan pesanan bahan baku plat $4 \times 8$ sebanyak 736 buah perbulan, untuk jadwal pemesanan dan kedatangan bahan baku dijadwalkan per minggu, jadi untuk tiap minggu barang akan datang sejumlah 184 buah selama satu bulan.

Tabel 11. MRP Mur \& Baut

\begin{tabular}{|c|c|c|c|c|c|c|c|c|c|c|c|c|c|}
\hline \multirow{2}{*}{\multicolumn{2}{|c|}{ Mur \& Baut }} & \multicolumn{12}{|c|}{ Bulas Juai 2019} \\
\hline & & \multicolumn{6}{|c|}{ Mingzu I } & \multicolumn{6}{|c|}{ Mingzu 2} \\
\hline & & \multirow{2}{*}{$\frac{1}{537}$} & \multirow[t]{2}{*}{2} & \multirow[t]{2}{*}{3} & \multirow[t]{2}{*}{4} & \multirow[t]{2}{*}{5} & \multirow[t]{2}{*}{6} & \multirow{2}{*}{$\frac{1}{537}$} & \multirow[t]{2}{*}{2} & \multirow[t]{2}{*}{3} & \multirow[t]{2}{*}{4} & \multirow[t]{2}{*}{3} & \multirow[t]{2}{*}{6} \\
\hline GR & & & & & & & & & & & & & \\
\hline $\mathrm{OH}$ & 2160 & 1623 & & & & & & 1086 & & & & & \\
\hline \multicolumn{14}{|l|}{$\mathrm{NR}$} \\
\hline \multicolumn{14}{|l|}{ PORer } \\
\hline \multicolumn{14}{|l|}{ PORel } \\
\hline & & \multicolumn{6}{|c|}{ Mfingze 3} & \multicolumn{6}{|c|}{ Mingsu 4} \\
\hline & & 1 & 2 & 3 & 4 & 5 & 6 & 1 & 2 & 3 & 4 & $s$ & 8 \\
\hline GR & & 537 & & & & & & 537 & & & & & \\
\hline $\mathrm{OH}$ & & 549 & & & & & & 12 & & & & & \\
\hline $\mathrm{NR}$ & & & & & & & & & & & & & \\
\hline PORec & & & & & & & & & & & & & \\
\hline POReI & & & & & & & & & & & & & 7 \\
\hline
\end{tabular}

Bahan baku mur \& baut dilakukan pemesanan pada akhir bulan juni 2019 sebanyak 540 pasang untuk memenuhi kebutuhan minggu pertama bulan juli 2019 yang dibutuhkan sebanyak 552 pasang, karena dibulan sebelumnya persediaan ditangan masih tersisa 12 pasang maka pesanan untuk minggu ini adalah 540 pasang. Untuk minggu selanjutnya dibutuhkan sebanyak 552 pasang, jadi bahan baku akan dipesan sebanyak 552 pasang karena metode yang di pakai ialah Lot for Lot.

Tabel 12. MRP Pipa Kotak 1,5 x 1,5

\begin{tabular}{|c|c|c|c|c|c|c|c|c|c|c|c|c|c|}
\hline \multirow{3}{*}{\multicolumn{2}{|c|}{$\begin{array}{c}\text { Pipa Kotak } \\
\text { 1.5xl.5 }\end{array}$}} & \multicolumn{12}{|c|}{ Bulan Juni 2019} \\
\hline & & \multicolumn{6}{|c|}{ Minggu 1} & \multicolumn{6}{|c|}{ Minggu 2} \\
\hline & & 1 & 2 & 3 & 4 & $\mathbf{5}$ & 6 & 1 & 2 & 3 & 4 & 5 & 6 \\
\hline GR & & 24 & & & & & & 22 & & & & & \\
\hline $\mathrm{OH}$ & 90 & 66 & & & & & & 44 & & & & & \\
\hline \multicolumn{14}{|l|}{ NR } \\
\hline \multicolumn{14}{|l|}{ PORec } \\
\hline \multirow{2}{*}{\multicolumn{14}{|c|}{ PORel }} \\
\hline & & & & & & & & & & & & & \\
\hline & & 1 & 2 & 3 & 4 & 5 & 6 & 1 & 2 & 3 & 4 & 5 & 6 \\
\hline GR & & 22 & & & & & & 22 & & & & & \\
\hline $\mathrm{OH}$ & & 22 & & & & & & 0 & & & & & \\
\hline \multicolumn{14}{|l|}{ NR } \\
\hline \multicolumn{14}{|l|}{ PORec } \\
\hline PORel & & & & & & & & & & & & & 0 \\
\hline
\end{tabular}


Bahan baku pipa kotak 1.5 x 1.5 pada bulan juni persediaan sudah habis maka perlu pemesanan pada bulan ini untuk kebutuhan bulan selanjutnya minggu pertama. Jadi pemesanan bahan baku pipa kotak $1.5 \mathrm{x}$ 1.5 sebanyak 23 batang untuk produksi minggu pertama bulan juli 2019. Dan pada bulan ini setiap minggu membutuhkan bahan baku pipa kotak 1.5 x 1.5 sebanyak 23 batang karena memakai metode dari Lot for lot jadi pemesanan dilakukan per minggu.

Tabel 13. MRP Kawat bendrat

\begin{tabular}{|c|c|c|c|c|c|c|c|c|c|c|c|c|c|}
\hline \multirow{3}{*}{\multicolumn{2}{|c|}{ Kawn Besdrat }} & \multicolumn{12}{|c|}{ Belan Juni 2019} \\
\hline & & \multicolumn{6}{|c|}{ Xingro 1} & \multicolumn{6}{|c|}{ MFge? } \\
\hline & & 1 & 2 & 3 & 4 & 5 & 6 & 1 & 2 & 3 & 4 & 5 & 6 \\
\hline GR & & 91 & & & & & & 89 & & & & & \\
\hline $\mathrm{OH}$ & 360 & 269 & & & & & & 180 & & & & & \\
\hline \multicolumn{14}{|l|}{ NR } \\
\hline \multicolumn{14}{|l|}{ PORec } \\
\hline \multicolumn{14}{|l|}{ PORd } \\
\hline & & \multicolumn{6}{|c|}{ Mlingse 3} & \multicolumn{6}{|c|}{ Mengse 4} \\
\hline & & 1 & 2 & 3 & 4 & 5 & 6 & 1 & 2 & 3 & 4 & 5 & 6 \\
\hline GR & & 39 & & & & & & 39 & & & & & \\
\hline $\mathrm{OH}$ & & 91 & & & & & & 2 & & & & & \\
\hline \multicolumn{14}{|l|}{ NR } \\
\hline \multicolumn{14}{|l|}{ PORee } \\
\hline PORel & & & & & & & & & & & & & 0 \\
\hline
\end{tabular}

Bahan baku kawat bendrat dibutuhkan sebanyak 91 di minggu pertama bulan Juni 2019, persediaan ditangan sejumlah 360 maka tidak dilakukan pemesanan. pemesanan dilakukan pada akhir bulan untuk mencukupi kebutuhan minggu pertama bulan Juli yaitu sebanyak 92 batang. Metode yang digunakan lot for lot sehingga pesanan disesuaikan dengan kebutuhan per minggu pada bulan ini dan selanjutnya.

\section{PENUTUP}

Kesimpulan dari analisis yang telah dilakukan, adalah :

1. Persediaan bahan baku yang diperoleh dari peramalan dengan metode linier regression yaitu 2.478 unit rak gantungan baju dengan rincian kebutuhan bahan baku yaitu pipa kotak $2 \times 4$ sebanyak 2.478 batang, plat 4x8 sebanyak 9.912 buah, mur dan baut sebanyak 29.736 pasang, pipa kotak $1.5 \times 1.5$ sebanyak 1.239 batang, dan kawat bendrat sebanyak 4.956 batang.
2. Hasil dari pengolahan data lot sizing dengan metode Economic Order Quantity, Lot for Lot, Period Order Quantity, Part Period Balancing, dan Wagner Whitin. Diperoleh metode yang paling optimal dengan biaya paling minimum ialah Lot for Lot dengan biaya sebesar Rp. 287.752,-, jika dibandingkan dengan metode lainnya yaitu POQ sebesar Rp. 287.904,-, EOQ sebesar Rp. 2.190.608,-, PPB sebesar Rp. 287.952,-, dan Wagner Whitin sebesar Rp. 287.952,--

\section{DAFTAR PUSTAKA}

Heizer, J., \& Render, B. (2006). Manajemen Operasi, Edisi 7. Salemba Empat, Jakarta.

Herjanto, E. (2007). Manajemen Operasi (Edisi 3). Grasindo.

Irwansyah, D. E., \& Hidayati, R. (2010). Penerapan Material Requirements Planning (Mrp) Dalam Perencanaan Persediaan Bahan Baku Jamu Sehat Perkasa Pada Pt. Nyonya Meneer Semarang. Universitas Diponegoro.

Nuriszal, F., \& Anshori, M. (2019). Perencanaan Persediaan Bahan Baku Untuk Produk Semen Instan di PT. VWX. JISO: Journal of Industrial and Systems Optimization, 2(1), 18-22.

Rovianty, A. N. (2007). Analisis Penerapan Material Requirement Planning (MRP) dalam Upaya Mengendalikan Persediaan Bahan Baku Daging Pada Long Horn Steak \& Ribs. Universitas Widyatama.

Tyas, D. S., \& Anshori, M. (2019). Penerapan Model Joint Economic Lot Size Pada PT. MPX Antara Pemanufaktur dan Multi Pembeli Dengan Permintaan Probabilistik. JISO: Journal of Industrial and Systems Optimization, 1(1), 2328.

Wijayanti, W., \& Adriansyah, G. (2019). Analisis Perencanaan Produksi Tas FLB di PT. X Mojokerto. JISO: Journal of Industrial and Systems Optimization, 1(1), 1-6. 